\title{
LANGUAGE
}

๙

\author{
Kateryna Laidler \\ Maria Curie-Skeodowska University (UMCS) in Lublin \\ k.laidler.umcs@gmail.com
}

\section{Online Adaptation of Word-initial Ukrainian CC Consonant Clusters by Native Speakers of English}

\begin{abstract}
The phenomenon of loanword adaptation occupies a prominent position in modern phonological literature. The present paper introduces the major theories which deal with this phenomenon as well as presenting the author's experimental study of online adaptation of Ukrainian word-initial CC consonant clusters illegal in English.

In this paper the findings of two experiments are compared and discussed. In the first one 25 native speakers of English imitated Ukrainian words containing word-initial CC consonant clusters absent in English. In the second task a different group of 25 native English speakers were asked to write down the same words in orthographic form. The analysis has shown certain similarities as well as differences between the two sets of data.

The repetition task demonstrates that the sonority profile of a cluster has a significant influence on the reproduction of a sequence. Thus, the combinations of sounds which comply with the Sonority Sequencing Generalization pose less difficulty for English native speakers than clusters which violate this principle. The study has also revealed the number of patterns which clearly show that the structure of the CC consonant cluster influences the repair strategy chosen by the participants. Thus, vowel epenthesis is frequently employed with two voiced obstruents, and consonant deletion seems to be the prevalent repair strategy in the case of fricatives.
\end{abstract}

Keywords: online adaptation, repair strategy, consonant clusters

\section{Introduction}

We are used to the fact that words borrowed from foreign languages have long become an inseparable part of the language at the receiving end of the process. Some of those words are changed to comply with the patterns in the borrowing language to such an 
extent that it is difficult to recognise them as loans, e.g. paper, pen, pain or noun in English, while others are adapted only partially and in some cases retain some of their original pronunciation or spelling, e.g. faux pas or rendezvous. The changes which the words undergo in the course of their transfer from one language to another are commonly referred to as 'adaptations' and can include changes on the level of sounds, morphological structure, or meaning. In the course of adaptation foreign words are brought as close to the rules operating in the target language as possible.

If we are asked to reproduce a word of a language that is not only unknown to us, but whose sound system is different from that in our mother tongue, we will usually end up altering its sounds in a number of ways. Most likely, our version will, naturally, contain the sounds of our native language or follow its phonetic rules. For example, if we ask a native speaker of English to pronounce the Ukrainian word [mtfatr], what you can often hear will be [mutfatr] or [mətfatı]. These alterations are due to the fact that the English language does not have the $[\mathrm{mg}]$ cluster in word-initial position, so the listener, whether they intend to or not, will obey the rules of their native language and break the 'illegal' sequence by inserting a vowel. Such adaptations that take place at the moment of speech, are called online adaptations.

Let us have a look at some examples of Japanese adaptations of English words. Japanese is a syllabic language, thus it puts restrictions on the sequences of consonants, e.g. such as the requirement that two consonants do not appear next to each other (Kay 1995; Smith 2005). For example, if we take the English word goodbye, which has two consonants next to each other, [d] and [b], in order to avoid such a sequence, a vowel is inserted between them, changing the pronunciation of the word into [gudobar]. Other examples include E. spirit - J. [supirito], E. Christmas J. [kurisumasu]. However, it can be claimed that in order to avoid the sequence of two consonants, another strategy might be applied, namely deletion of one of the elements within the illicit sequence. Nevertheless, Japanese exhibits a certain consistency in how foreign words are adapted, i.e. vowel insertion is without fail preferred over elision. One of the questions that loanword phonology is trying to answer is why certain strategies are chosen over others and more importantly, at what stage these changes are introduced. Do the Japanese actually hear the word as [kurisumasu] and because of it reproduce it in such a way, or perhaps they hear it as any other native speaker of English, but because the languages are so different they are simply unable to articulate it as [krismas]. The question is whether adaptations are introduced as early as at the stage of perception or maybe they take place only later in production or perhaps it is the combination of the two. Recent studies of loanword adaptation assume two main positions: the phonetic and the phonological approximation stance. The phonetic view on loanword adaptation puts acoustic similarity in the centre of attention. In other words, perceptual similarity determines the way L2 forms are mapped onto L1 forms. However, the researchers favouring the other approach claim that it is phonology that plays an important role in the process. The perceptual biases of the L1 phonological system are thought to influence the faithfulness in the perception of L2 
forms. According to this explanation, modifications in the form of loanwords occur because the borrowers are non-native speakers of L2 and thus their perception of L2 forms is unreliable. The phonetic view is strongly supported by Peperkamp (2005, 350 ) in a series of papers in which she argues that actually all transformations are the result of unfaithful perception of L2: 'loanword adaptations are basically phonetic rather than phonological in nature, and originate in the process of phonetic decoding during speech perception.' Phonological features of the target language may even be unknown to the borrower; thus, they do not play any role. Peperkamp \& Dupoux $(2003,368)$ state that, 'a given input sound will be mapped onto the closest available phonetic category'. If this approach is assumed, the number of target-like reproductions should be extremely rare since ill-formed structures should be altered without exception in order to fit the phonological system of the target language.

On the other hand, according to LaCharite \& Paradis (2005), the underlying representation of a loanword is similar to the form found in the source language and the phonological grammar of the borrowing language maps the underlying representation onto the surface representation. As a part of this process, some alterations or adaptations to a loanword may be introduced in order to meet the requirements of the borrowing language. To account for the principles responsible for adaptation, Paradis and LaCharité (1997) offer the theory of Constraints and Repair Strategies (TCRS). The main assumption of TCRS is the existence of constraints within the phonology of a particular language, which when violated trigger the repair strategies. Paradis and LaCharité $(1997,384)$, define repair strategy as:

A universal, non-contextual phonological operation that is triggered by the violation of a phonological constraint, and which inserts or deletes content or structure to ensure conformity to the violated constraint.

Within this framework there is the Preservation Principle, which will resist the loss of segments. According to Paradis and LaCharité (1997), choosing a repair strategy in adaptations is often a question of perspective. For example, the adaptation of a consonant cluster (CC) input in a language with a constraint against such clusters can theoretically go in two different directions: a) treating it as an excess of consonants and deleting one consonant as a result; b) regarding it as a lack of a vowel, which will lead to the insertion of one. According to the Preservation Principle, which resists the loss of segments, the preferred strategy in such a case would be an insertion rather than a deletion of a segment. Even though both repair strategies will satisfy the constraints, only the former maximally preserves the input. This inviolable principle is limited, however, by the Threshold Principle, which determines the number of possible steps for the repair process. If adaptation of a segment requires more than two steps, it is considered too costly and the segment is often deleted. The implication of these principles is that the favoured repair strategy in the loanword adaptation process is epenthesis (i.e. vowel insertion), since it preserves the maximum of phonological content. 


\section{Experimental design}

The aim of the experiment reported in this paper was to see how English native speakers would deal with the word-initial consonant clusters that do not appear in English. Which repair strategies would they apply and would those strategies depend on the structure of the clusters? The goal was also see which of the major theories of loanword adaptation (phonetic or phonological) could explain the data obtained in the experiment.

\subsection{Experimental material}

For the purpose of the experiment a list of 56 Ukrainian words was constructed. Each of those words contained a word-initial consonant cluster which does not appear in English. These clusters fell into four categories:

- sonorant + sonorant (e.g. [mlosno], [mrjatka], [mni:xi])

- obstruent + sonorant (e.g. [zlada], [gmax], [dljatt])

- sonorant + obstruent (e.g. [rvutko], [rdest], [lvi:v])

- obstruent + obstruent (e.g. [ptax], [gvalt], [vzami:n]).

These words were randomised in order to avoid the sequences of clusters with a similar quality and recorded by a female native speaker of Ukrainian with 3-5 seconds intervals between them.

\subsection{Participants}

The participants of the experiment were 25 native speakers of British English varieties between 25 and 32 years old. Some of them were recruited at the University of Sussex, others had obtained their degrees by the time of the experiment. None of the participants reported any knowledge of Ukrainian or any other Slavic language.

\subsection{Analysis}

The responses to the first part of experiment were analysed auditorily as well as with the aid of wide-band spectrograms created with the aid of Speech Analyzer 3.1 software. The words reproduced by the participants were classified into four main groups according to the repair strategies applied by the participants:

- Vowel epenthesis. The vowel was inserted between two consonants, which led to a well-formed segment. For example, words like [mtfatı] or [gmax] were often pronounced as [mutfati] and [gəmax];

- Consonant deletion. Another frequently used strategy, when one of the consonants within an ill-formed cluster is simply deleted. In the experiment [ptax] was sometimes changed into [tax], [tnutr] became [nutr]; 
- Cluster modification. The most frequent cases included a change of voicing, place or manner of articulation in one of the segments. For example, [fvatfka] was changed into [3vatfka] and [xvoja] into [kvoja].

Some of the responses were difficult to classify because they were either incomprehensible or several different repairs were used simultaneously - in such cases they were put under the category 'other'. Of course, some participants were more successful in their attempts to reproduce the words and if the cluster was pronounced correctly, it was classified as target-like.

\section{Results}

Figure 1 shows the frequency with which the repair strategies were used by the participants in each of the sound groups. As can be seen, the majority of target-like productions were found in the obstruent-sonorant clusters, while other combinations of sounds were usually repaired by the native speakers. Thus, sonorant-sonorant clusters were repaired by means of a vowel insertion in $36.3 \%$ of cases; however, epenthesis was even more frequent in the words that included sonorant-obstruent sequences, where it reached its peak of $39.27 \%$. The least homogeneous group is the obstruent-obstruent cluster type, since there is no clear preference of a particular repair strategy observed. Obstruent-obstruent clusters as well as those from the sonorant-obstruent group posed particular difficulty to the participants, since only $20 \%$ and $18 \%$ of them respectively were reproduced successfully.

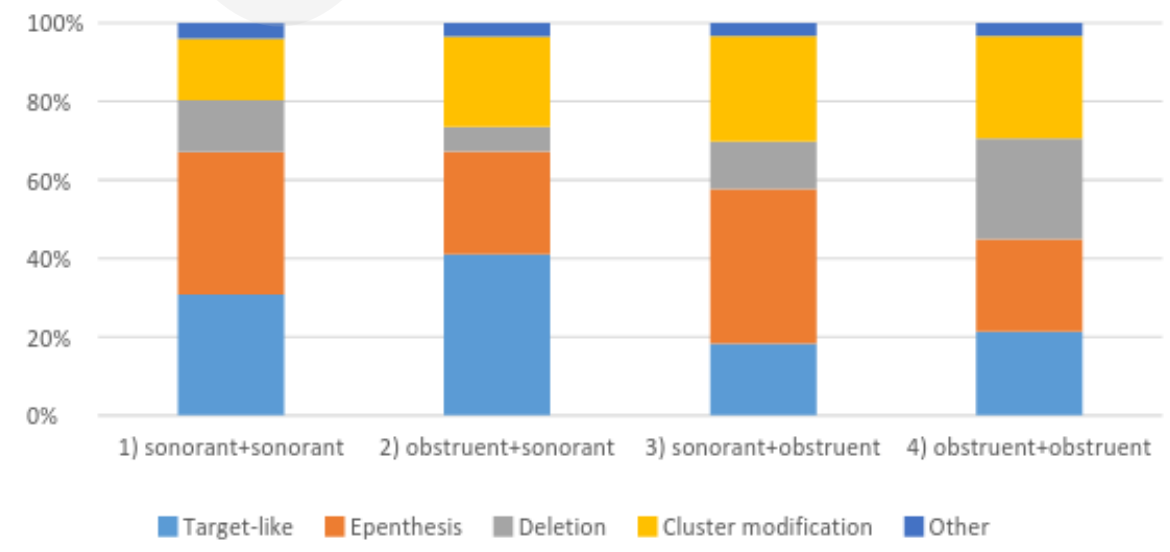

Figure 1. The summary of all clusters in the repetition task

As can be seen from Figure 1, the preferred adaptation strategy in the sonorant-sonorant group of clusters is a vowel insertion, with target-like productions being the second most frequent response. 
An important factor to be considered is the sonority profile of these clusters. The sonority hierarchies proposed in the phonological literature (Steriade 1982, Selkirk 1984) often vary in details but all present a similar sequence: stops are the least sonorous and are followed by fricatives, nasals, liquids, glides and finally vowels:

stops $>$ fricatives $>$ nasals $>$ liquids $>$ glides $>$ vowels

This can account for an accurate imitation in the obstruent-sonorant group of clusters where target-like reproduction very often reaches almost $50 \%$ or even more with, for example, [zl] being produced correctly by $64 \%$ of the participants or [zm] by $60 \%$. Such a successful reproduction of the consonant sequences can be explained with the conformity of the clusters to the sonority profile of a well-formed syllable. The most difficult cluster, on the other hand, was [dn], with only $16 \%$ of target-like responses. Even though the consonant sequences in this group of stimuli are illegal in word-initial position English, their sonority increases, which can explain the ease with which these clusters were imitated.

The clusters in the sonorant-obstruent group were often repaired by epenthesis (in $40 \%$ of cases) and the ratio of target-like productions was the lowest across the groups: just below $20 \%$. The clusters within the sonorant-obstruent group show falling sonority, which is fine for the Ukrainian language, but not for English. Because the first element in such clusters shows higher sonority, participants very often hear two syllables instead of one, which also explains why they often reproduced those words with an inserted vowel.

The results obtained for the obstruent-obstruent clusters also contain some interesting patterns. It is difficult to generalise about the preferred repair strategy for the group of clusters as a whole as the responses were almost equally distributed. Thus, certain patterns were analysed with a focus on the segmental structure of the clusters.

The instances of epenthesis were the most frequent in the following clusters:

$$
\begin{array}{ll}
\text { plosive }+ \text { plosive } & {[\mathrm{kp}]-44 \%} \\
\text { plosive }+ \text { affricate } & {[\mathrm{bd}]-40 \%} \\
\text { fricative }+ \text { affricate } & {[\mathrm{zf}]-40 \%} \\
\text { plosive }+ \text { fricative } & {[\mathrm{gv}]-36 \%} \\
\text { fricative + fricative } & {[\mathrm{vz}]-32 \%,[\mathrm{zz}]-28 \%}
\end{array}
$$

Most of them, though not all, are combinations of voiced sounds. An explanation of such a tendency can be found in Fleischhaker (2002), who claims that vowel insertion is auditorily perceived as less intrusive when found in the combination of voiced consonants than in the case of voiceless sequences. However, the irregularities with respect to the repair strategy in question require further analysis and explanation of the data collected.

Deletion dominated as a repair strategy in the following clusters:

fricative + fricative $[\mathrm{sx}]-64 \%$

affricate + fricative $[\mathrm{t} \mathrm{x}]-64 \%$

fricative + fricative $\left[\int \mathrm{x}\right]-60 \%$

plosive + fricative $\left[\mathrm{p} \int\right]-48 \%$

fricative + fricative[z3] $-40 \%$ 
The clusters within the obstruent-obstruent group included seven voiceless sequences, for five of which the dominant repair strategy was deletion and only one such cluster was adapted by means of an epenthetic vowel ([kp] $>[\mathrm{k} ə \mathrm{p}])$. This pattern once again verifies the claim that epenthesis is dispreferred in voiceless clusters, and, apparently, the speakers tend to delete one of the elements of a cluster in order to conform to the rules of native phonology. The segment that is removed by the majority of participants is the voiceless velar fricative, which might be connected with its absence from the English inventory and the resultant difficulty in identifying it by English native speakers.

With regard to cluster modification as a dominant repair strategy, several generalisations can be made. First, fricative-fricative combinations seem to undergo this type of change more frequently than other combinations: $\left[\int \mathrm{v}\right]-60 \%$, [xv] $-56 \%$, [fz] $-48 \%$ with one of the elements being either changed in voicing (e.g. $\left[\int \mathrm{v}\right]>[3 \mathrm{v}]$ ) or manner of articulation (e.g. $[\mathrm{xv}]>[\mathrm{kv}])$. Only one cluster in which a segment change was preferred over other strategies is affricate-stop ([tft] - 52\%). Secondly, the majority of these combinations contain a voiceless element, which was often changed to a voiced one, as in $\left[\int \mathrm{v}\right]>[\mathrm{zv}]$ or $[\mathrm{fz}]>[\mathrm{vz}]$. This is quite surprising, considering that such a change did not always result in a legal $\mathrm{CC}$ consonant cluster and that voice assimilation does not appear in English, except for inflectional endings.

\section{Conclusions}

The experiment has shown certain patterns in how repair strategies tend to be applied:

1) Sonority profile of clusters seems to be of great importance because most target-like reproductions are found among clusters which follow the rising sonority profile. Besides, clusters in which this rule is violated are very often repaired by means of epenthesis, e.g. [mtg] - 64\%, [m3] - 56\%, [13] - 56\%.

2) Vowel insertion is more common in clusters which consist of voiced sounds and especially if they include obstruents, e.g. [bdb] - 40\%; [zt'] - 40\%. One possible explanation may be that insertion of a vowel, which results in a voiced sound between two other voiced sounds, is auditorily perceived as less intrusive than if it is inserted between voiceless ones.

3) Deletion is usually found in the clusters which consist of voiceless consonants, e.g. $\left[\mathrm{p} \int\right]-48 \%,[\mathrm{t} \mathrm{x}]-64 \%$. When it comes to the place of articulation, alveolar sounds are deleted more frequently than other types. If the manner of articulation is taken into account, the sounds which tend to be preserved are fricatives. One more observation that should be mentioned is that a sound which does not belong to the English inventory is deleted in the vast majority of cases rather than repaired using other strategies. In our experimental material this was found for the voiceless velar fricative $[\mathrm{x}]$.

4) Some general patterns concerning modifications of clusters are the following:

- the most commonly used modifications are change in voicing or in the manner of articulation; 
- the combination of sounds that was most frequently modified is fricative-fricative, for example $/ \mathrm{fv} /-60 \%$, $/ \mathrm{xv} /-56 \%$, /fz/ - $48 \%$.

Some patterns discovered in the course of the experiment can be explained through the phonetic approach, while others can be accounted for by the phonological one. The results of the experiment have shown general preference for vowel insertion over deletion of segments, which provides evidence for the TCRS model within the phonological approach towards loanword adaption. At the same time the perceptual model strongly advocated by Peperkamp (2005) does not seem to account for the data of our experiment, since a substantial number of ill-formed clusters were produced by English native speakers quite successfully. As was mentioned above, this was the most frequent case in the clusters with the rising sonority profile. Nevertheless, some further work and analysis is required in order to fully account for the regularities found in the experiment described in this paper.

\section{References}

Fleischhacker, H. 2002. "Cluster-dependent epenthesis asymmetries.” UCLA Working Papers in Linguistics 7, Papers in Phonology 5: 71-116.

Kay, Gillian S. 1995. Loanwords in Contemporary Japanese. Cambridge: Cambridge University Press.

LaCharite, D., and C. Paradis. 2005. "Category preservation and proximity versus phonetic approximation in loanword adaptation." Linguistic Inquiry 36: 223-258.

Paradis, C., and D. LaCharité. 1997. "Preservation and minimality in loanword adaptation." Journal of Linguistics 33: 379-430.

Peperkamp, S. 2005. "A psycholinguistic theory of loanword adaptations." In Proceedings of the 30th Annual Meeting of the Berkeley Linguistics Society, eds. M. Ettlinger, N. Fleischer, and M. Park-Doob, 341-352. Berkeley, CA: The Society.

Peperkamp, S., and E. Dupoux. 2003. "Reinterpreting loanword adaptations: the role of perception." In Proceedings of the 15th International Congress of Phonetic Sciences, eds. M. J. Solé, D. Recasens, and J. Romero, 367-370. Barcelona: Causal Productions.

Selkirk, E. O. 1984. "On the major class features and syllable theory.” In Language sound structure, eds. M. Aronoff and R. Oerhle, Cambridge: MIT Press.

Smith, Jennifer L. 2005. "Loan phonology is not all perception: evidence from Japanese loan doublets." In Japanese/Korean Linguistics 14, ed. Timothy J. Vance. Stanford: CSLI.

Steriade, Donca. 1982. "Greek prosodies and the nature of syllabification." Doctoral Dissertation, MIT, Cambridge, Mass., USA. 